\title{
Correction to: Moringa oleifera leaf extracts attenuate Complete Freund's adjuvant-induced arthritis in Wistar rats via modulation of inflammatory and oxidative stress biomarkers
}

\author{
Ammara Saleem $^{1}$ (D) $\cdot$ Mohammad Saleem ${ }^{1,2} \cdot$ Muhammad Furqan Akhtar $^{3} \cdot$ Muhammad Shahzad $^{4} \cdot$ Shah Jahan $^{5}$
}

Published online: 4 September 2019

(c) Springer Nature Switzerland AG 2019

\section{Correction to: Inflammopharmacology https://doi.org/10.1007/s10787-019-00596-3}

In our article entitled "Moringa rivae leaf extracts attenuate Complete Freund's adjuvant-induced arthritis in Wistar rats via modulation of inflammatory and oxidative stress biomarkers", we described the anti-arthritic effects of the plant leaves from Pakistan that we referred to as Moringa rivae (Saleem et al. 2019). Unfortunately, the identity of the plant material was incorrect. In fact, the plant leaves under study were later identified as belonging to wild type Moringa oleifera Lam. rather than Moringa rivae Chiov.

After the publication of this article it was raised to the editor's attention by Prof. Mark Olson that Moringa rivae does not occur in Pakistan and may be dangerous to the general population if used wrongly on the basis of this study. Moringa rivae is endemic to northeast Africa, in northern Kenya, southeastern Ethiopia, and possibly southern Somalia (Thulin 1993; Olson 2002). It does not occur outside the

The original article can be found online at https://doi.org/10.1007/ s10787-019-00596-3.

Ammara Saleem

amarafurqan786@hormail.com

$\triangle$ Mohammad Saleem

saleem2978@ hotmail.com

1 Department of Pharmacology, Faculty of Pharmaceutical Sciences, Government College University Faisalabad, Faisalabad, Pakistan

2 Department of Pharmacology, University College of Pharmacy, University of the Punjab, Lahore, Pakistan

3 Riphah Institute of Pharmaceutical Sciences, Riphah International University, Lahore Campus, Lahore, Pakistan

4 Department of Pharmacology, University of Health Sciences, Lahore, Pakistan

5 Department of Immunology, University of Health Sciences, Lahore, Pakistan
Horn of Africa and does not occur in Pakistan. The two species of Moringa that have been documented from Pakistan are $M$. oleifera, which is widely cultivated throughout the lowlands there as in all tropical countries, as well as M. concanensis Nimmo, which is known from tropical deciduous forests in Balochistan and Sindh Provinces, as well as from numerous localities in India and into Bangladesh (Naderuzzaman et al. 1996). As often happens with poorly-studied plants in tropical countries with high diversity, the identity of Moringa species in Pakistan has been historically somewhat confused. The available identification keys (e.g. Qaiser 1973) are vague and do not correspond well to biological reality. For example, Qaiser's key specifies that M. concanensis usually has bipinnate leaves and M. oleifera usually has tripinnate leaves. Instead, as ongoing work on identification keys for the Indian subcontinent species (Olson and Garima, unpublished) shows, pinnation orders increase with leaf size, so small leaves of M. oleifera are often bipinnate, and large leaves of $M$. concanensis are often tripinnate. Complicating things further is that, in addition to the commonly cultivated domestic form of Moringa oleifera, there is another entity that occurs wild in the lowest reaches of the northwest Indian Shivalik range, and which is cultivated in lowlands from southeastern Pakistan to Bihar, India (Olson 2017). Although its relationship to the domesticate has yet to be established, this entity has been traditionally regarded as the wild type of Moringa oleifera, and has been presented as such in numerous publications (Duthie 1903). It is distinct from the domesticate in its seed morphology, leaves, flowers, and growth habit. Photographs of the material examined by Saleem et al. (2019) corresponds closely to this putatively wild type Moringa oleifera.

It has recently been shown that putative wild type Moringa oleifera differs markedly in its phytochemistry from domestic Moringa oleifera (Chodur et al. 2018; Fahey et al. 2018). The two entities differ markedly in the ways that they are used, with domestic M. oleifera eaten frequently, 
especially in southern India, and the putative wild type being used chiefly medicinally (Olson 2017; Chodur et al. 2018). Most studies of the applied properties of Moringa are carried out on the domestic variant of Moringa oleifera, meaning that the other species are very poorly studied. Because it is an important medicinal plant in parts of India and Pakistan, documentation regarding the properties of the putative wild type of M. oleifera is of great interest.

That Moringa species have so much promise with regard to their applied properties and are so poorly studied underscores the need for correct identification of the material studied, and the need for collaboration between applied scientists and taxonomic experts. Moringa rivae is never eaten as a food in its area of occurrence, but it is frequently used medicinally, especially to treat parasite infections in livestock, either by topical application or feeding to animals (Olson 2017). Local people report only rarely using the plant medicinally for humans, and then cautiously (Olson personal observation). Therefore, the status of Moringa rivae as edible or otherwise suitable for normal human consumption remains to be determined. Misidentification of material could lead to people attempting to consume material that is potentially harmful, as could be the case for M. rivae. By the same token, researchers or clinicians interested in exploring the use of wild type $M$. oleifera would be unable to do so because of the incorrect identification of the material. Collaboration with taxonomic experts and careful documentation of the material studied is therefore essential to maximize the potential benefits from Moringa and any other natural product.

Part of this documentation involves voucher specimens deposited in recognized herbaria, as well as scientifically rigorous photographs. Herbaria are "libraries" of dried plant specimens mounted on paper, with information regarding the locality and date of collection. Such specimens should always be available for consultation so that doubts about

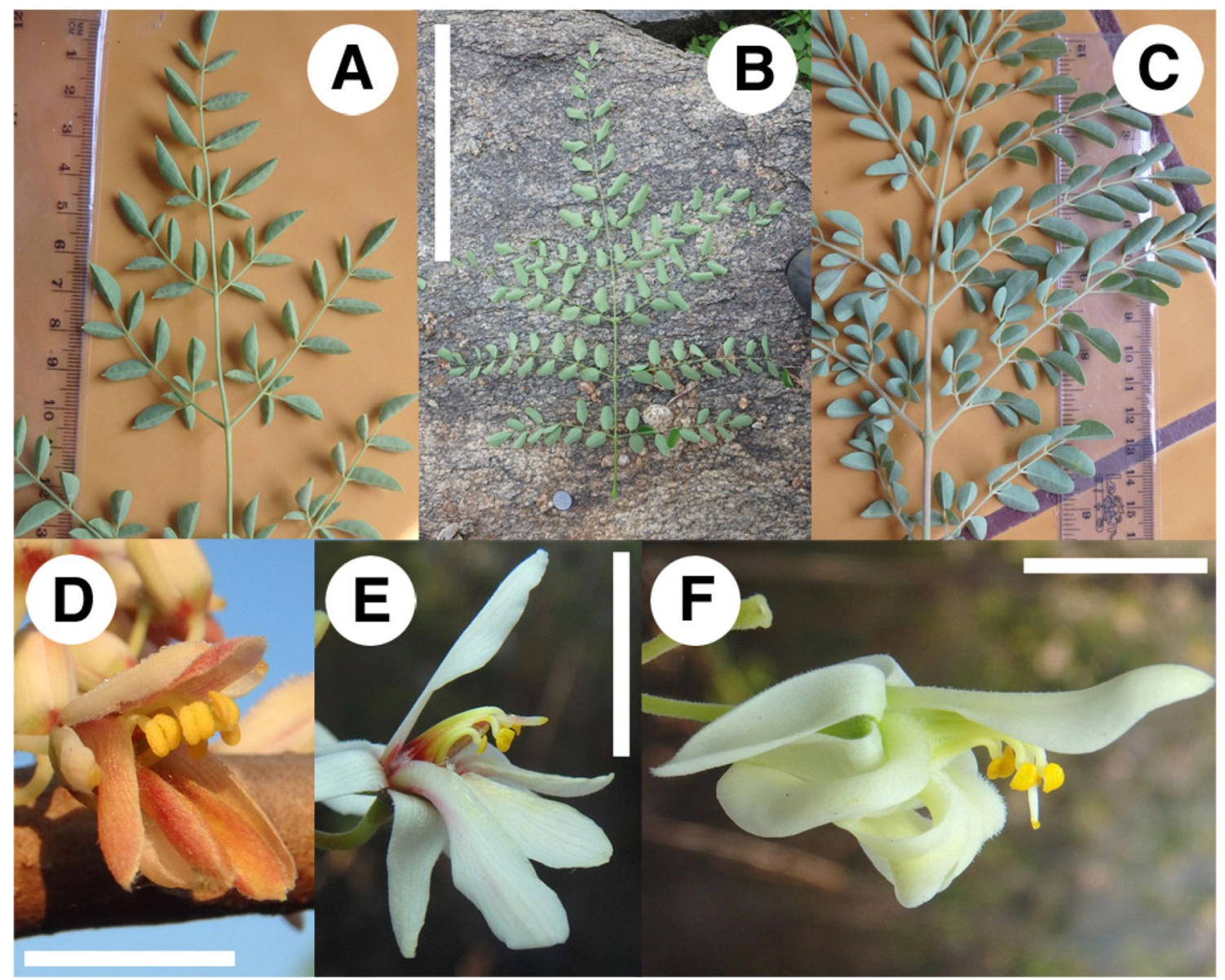

Fig. 1 Moringa species mentioned. a-c Leaves. a Moringa rivae. b Moringa concanensis has leaves with large leaflets. This leaf is bipinnate. c "Wild type" Moringa oleifera has leaves with much smaller leaflets than M. concanensis, and is usually 3-5 pinnate. d-f Flowers. d Moringa rivae has small flowers with whitish sepals and reddish to reddish brown petals. e Moringa concanensis has smaller flowers than domestic $M$. oleifera, with narrower petals and sepals that are almost always tinged red at their bases. f Domesticated M. oleifera, the most commonly cultivated species worldwide, has relatively large flowers that can be tinged with pink, or, as in this individual, be entirely cream-colored. Scale in $\mathbf{b} 30 \mathrm{~cm}$. Scale in d-f $10 \mathrm{~mm}$ 
the identity of the material used in a given study can be addressed immediately. Likewise, photographs showing the diagnostic features of a given species, including appropriate scales and reasonable sample sizes of the organs being photographed, are also essential. In conclusion, the material studied in Saleem et al. (2019) was the putative wild type of Moringa oleifera, not M. rivae, and the species studied represents a widely used medicinal plant in the Indian subcontinent, but one that is very poorly studied and whose medicinal potentials have only begun to be explored.

Acknowledgements We are greatly thankful to Prof. Mark E. Olson, Instituto de Biología, Universidad Nacional Autónoma de México, Mexico for his contribution in identifying the plant material and helped in drafting this Correction.

\section{References}

Chodur GM, Olson ME, Wade KL, Stephenson KK, Nouman W, Fahey JW (2018) Wild and domesticated Moringa oleifera differ in taste, glucosinolate composition, and antioxidant potential, but not myrosinase activity or protein content. Sci Rep 8(1):7995-8005

Duthie J (1903) Flora of the upper gangetic plain and of the adjacent Siwalik and sub-Himalayan tracts. Office of the Superintendent of Government Printing, Calcutta
Fahey JW, Olson ME, Stephenson KK, Wade KL, Chodur GM, Odee D (2018) The diversity of chemoprotective glucosinolates in Moringaceae (Moringa spp.). Sci Rep 8(1):7994-8003

Naderuzzaman ATM, Zahan SK, Ahad A (1996) Moringa concanensis Nimmo ex Daiz \& Gibbs: a new angiospermic record for Bangladesh. Bangladesh J Bot 25(1):111-112

Olson ME (2002) Combining data from DNA sequences and morphology for a phylogeny of Moringaceae (Brassicales). Syst Bot 27:55-74

Olson ME (2017) Moringa frequently asked questions. In: ISHS, Acta Horticulturae, vol 1158. https://doi.org/10.17660/actahortic .2017.1158.4

Qaiser M (1973) Moringaceae. Flora West Pak 38:1-4

Saleem A, Saleem M, Akhtar MF, Shahzad M, Jahan S (2019) Moringa rivae leaf extracts attenuate Complete Freund's adjuvantinduced arthritis in Wistar rats via modulation of inflammatory and oxidative stress biomarkers. Inflammopharmacology. https:// doi.org/10.1007/s10787-019-00596-3

Thulin M (1993) Flora of Somalia, vol 1. Royal Botanic Gardens, Kew

Publisher's Note Springer Nature remains neutral with regard to jurisdictional claims in published maps and institutional affiliations. 